\title{
Correlation of Evolutionof IT-Environment With Levels of Organizational Development: Reaching Teal-Level Maturity Through Losses Elimination
}

\author{
Efimova O.V. \\ Russian University of Transport, \\ Moscow, Russia, \\ ovefimova@mail.ru \\ Morgunov V. \\ Russian University of Transport, \\ Moscow, Russia, \\ hevding@mail.ru
}

\author{
Baboshin E.B. \\ Russian University of Transport, \\ Moscow, Russia, \\ evbaboshin@mail.ru \\ Karlov A.V. \\ Russian University of Transport, \\ Moscow, Russia, \\ artkarlov@gmail.com
}

\begin{abstract}
Development of the world's economic model in the post-industrial period has led to evolutionary shifts in the concept of development of organizations: once effective models of authoritarian corporations are being transformed into selforganizing sets of economic units united by goals, principles and functions. Digital technologies and the IT industry, which pioneered through evolutionary development concepts, play a significant role in this transformation. This article explores correlation between the level of digital maturity in the process of organizational evolution based on the theory of "teal" organizations, and provides an overview of economic losses that are being eliminated during this evolution. It defines the relationship between the stages of development of an organization, its IT functions and risks associated with economic losses that arise at one stage or another. Regularities and key factors influencing the evolutionary changes in the context of IT transformation have been identified, and recommendations have been given on how to eliminate the corresponding losses.
\end{abstract}

Keywords-digital economy, teal organisations, losses elimination, organisational evolution, IT

\section{INTRODUCTION}

In today's world evolution of management systems is essentially linked to digital transformation [1]. Desynchronisation of organizational transformation processes and IT development in businesses can lead to efficiency losses both in organizational transformation and in the development and implementation of new digital services and information systems [2]. The principle of complementarily [3] in the management of all types of assets and changes means that the value of transforming two or more assets jointly is higher than transforming each of them separately. Typically, budget allocation for their acquisition and readiness of technical staff for development and implementation of IT evolution steps are often cited as the key success factors in the development of digital assets. [4]. However, it seems necessary to add a new factor - a factor of organizational maturity, the readiness of the organization to move to a transformed process. Synchronized development of the organizational model and digital transformation models is therefore the only way to make them effective.

\section{RESULTS AND DISCUSSION STAGES OF ORGANIZATIONAL DEVELOPMENT}

\section{A. Modern theories of organizational development}

Let us take a closer look at the main stages of development of organizational models and IT maturity levels. The evolutionary stages of organizational models considered in this article are based on the concept of spiral dynamics, which was formed in the works of scientist Claire William Graves [5] in the 1960s and later developed in the works of his students, Don Beck and Chris Cowan [6].

This concept depicts the individual and the development of his or her worldview in a spiral way - in the process of change. So, in that concept, people and society go through stages that have common features. Each of the following stages to a certain extent includes the characteristics of the previous one. For the sake of clarity, each stage of development has been given a certain colour. In 2014, Frederick Laloux [7] similarly "painted" organizations so that the dynamics of a company's organizational system lay within 
the spectrum of the rainbow: from infrared, which corresponds to its most primitive forms of organization, to teal.

It is the teal level of process organization that is the desired point of achievement in modern economic conditions, which allows the maximum development potential of business processes to be revealed. Let us consider this paradigm in more detail.

\section{B. Key features of teal organisantion models}

According to the evolutionary concept any teal organization rests on three principles: evolutionary purpose, wholeness and self-management [8]. These principles are universal for any modern company, but in the theory of future organizations these categories reveal themselves in the most "honest" way. Let us consider the features of the "teal approach" using its ideology as an example.

\section{Evolutionary purpose}

Many confuse the evolutionary purpose with the mission. The difference shows up when companies make decisions, when the mission or evolutionary purpose diverges from the possibility of earning money. An honest company with a mission rewrites it so that it extends to the new kind of earning. A dishonest company earns money without changing its mission. A company with an evolutionary purpose does not do what is not necessary to achieve the goal, even if it can generate income. The company writes its mission for its own needs; in the case of an evolutionary purpose, the company is created for it. It turns out that the evolutionary purpose is more important than the company. This is why a company with an evolutionary purpose has no competitors, because they all help to fulfill it and transform it into a teammate. An evolutionary purpose is a flag that is raised by someone and gathers around those who coincide in values.

Paradoxically, by focusing less on the bottom line and shareholder value, companies with a purpose generate financial results that outpace those of competitors.

\section{Wholeness}

Wholeness is when employees are no longer perceived as human resources and start to perceive them and themselves as living people with all their needs and emotions, even if they are not really needed for work. It is well known that the dress code, work schedule and the plans that come down from above hamper integrity and are therefore not welcome in teal organizations. Also, teal organizations do not separate personal life and work, because this is all part of one whole. Therefore, in such companies, no one will ask you to leave your personal life outside the office door and be just a good screw in the system. They create an environment wherein people feel free to fully express themselves, bringing unprecedented levels of energy, passion, and creativity to work.

\section{Self-Management}

The basis of the teal approach is self-management, which is manifested in each company by an individual set of practices. Often the classic management is maintained in separate areas: operations, accounting. At the same time, there are independent teams with their own area of responsibility. For example, in a bank, there is a group of separate branches or a group that is responsible for creating a new website, a mobile application. The top manager can work as part of the teal team and take on new roles - for example, answering customer questions together with the support team. Companies set up structures and practices in which people have high autonomy in their domain, and are accountable for coordinating with others. Power and control are deeply embedded throughout the organizations, no longer tied to the specific positions of a few top leaders.

The combination of these practices indicates a fundamentally new evolutionary stage in organizational development [9], which requires a reconsideration of approaches also in related evolutionary environments, in this case in the IT-environment.

\section{STAGES OF DEVELOPMENT OF IT-ENVIRONMENT AND CORRESPONDING LOSSES THAT EMERGE IN CASE OF LACK OF SYNCHRONIZATION WITH ORGANIZATIONAL TRANSFORMATION}

IT systems development is one of the "tealest" industries in the world. IT teams have long been building teamwork on flexible methodologies, implementing individual Agile practices [10] (e.g. from Scrum or Kanban frameworks) and dividing tasks into short sections to accelerate release. These processes require a high level of responsibility and a change in the cultural approach to work [11]: both for each staff and for the entire team.

Organizational development issues in IT organizations are linked tightly to IT maturity phenomenon. Organizations with a lower IT maturity level tend have inefficient operations, inconsistent quality of work, and trouble adapting quickly when business needs change. Companies with a higher level of IT maturity have standardized processes, consistency in their quality of output, and the ability to adjust to business growth more easily.

At the same time, according to the industry-standard guidelines ITIL (Information Technology Infrastructure Library) guidelines [12], the IT-environment undergoes certain stages of evolution - regardless of whether it is a "large" organization or a small start-up. An approximate evolution pattern is described in the table below.

TABLE I. IT-ENVIRONMENT EVOLUTION STAGES

\begin{tabular}{|l|l|}
\hline IT-environment evolution stage & \multicolumn{1}{c|}{ Peculiarities } \\
\hline Patchwork automation & $\begin{array}{l}\text { Project work on automation for } 3^{\text {rd }} \\
\text { parties }\end{array}$ \\
\hline $\begin{array}{l}\text { IT as a part of the core business } \\
\text { infrastructure }\end{array}$ & Linear service tasks \\
\hline Service model & $\begin{array}{l}\text { Integration of solutions at corporate } \\
\text { level, creation of management systems, } \\
\text { involvement in processes }\end{array}$ \\
\hline Ecosystem & $\begin{array}{l}\text { Platform solutions for external users } \\
\text { that combine internal services }\end{array}$ \\
\hline IT-Prime - holacracy & $\begin{array}{l}\text { Management of platform business } \\
\text { solutions through full AI-based } \\
\text { automation }\end{array}$ \\
\hline
\end{tabular}

Although these evolutional stages have been known for some time many enterprises are not yet ready, even today, to manage their evolution through rapid development via smart analytical tools for production lines, where the application of business analytics may seem obvious.

The following analytical model traces correlations and parallels between the stages of IT organizational development, their management culture [13] and the stages of evolution of organizations. 


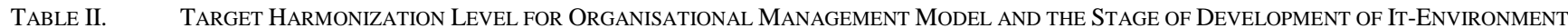

\begin{tabular}{|c|c|c|c|c|c|}
\hline \multirow[b]{2}{*}{$\begin{array}{l}\text { Stage of development } \\
\text { of organizational } \\
\text { management model }\end{array}$} & \multirow[b]{2}{*}{ Principles } & \multirow[b]{2}{*}{$\begin{array}{c}\text { Stage of } \\
\text { development IT- } \\
\text { environment }\end{array}$} & \multirow[b]{2}{*}{ Features } & \multicolumn{2}{|r|}{ Losses } \\
\hline & & & & $\begin{array}{c}\text { Losses of } \\
\text { organizational } \\
\text { model }\end{array}$ & $\begin{array}{l}\text { Losses of IT-environment } \\
\text { maturity stage }\end{array}$ \\
\hline Impulsive (red) & $\begin{array}{l}\text { Division of labor } \\
\text { Top-down } \\
\text { management }\end{array}$ & $\begin{array}{l}\text { Patchwork } \\
\text { automation }\end{array}$ & $\begin{array}{l}\text { Lack of IT strategy } \\
\text { Automation of individual } \\
\text { operations ("patchwork" } \\
\text { automation) } \\
\text { Outsourcing of tasks to } \\
\text { third parties }\end{array}$ & $\begin{array}{l}\text { Lack of clarity for } \\
\text { automation goals, } \\
\text { lack of effectiveness } \\
\text { Redundant } \\
\text { operations that do } \\
\text { not add value }\end{array}$ & $\begin{array}{l}\text { Mass losses of manual } \\
\text { labour, loss of time of the } \\
\text { organization's employees }\end{array}$ \\
\hline Conformist (brown) & $\begin{array}{l}\text { Recurring processes } \\
\text { Hierarchical } \\
\text { management model of }\end{array}$ & $\begin{array}{l}\text { IT-environment } \\
\text { considered as a } \\
\text { part of the core } \\
\text { business } \\
\text { infrastructure }\end{array}$ & $\begin{array}{l}\text { Internal IT department, } \\
\text { Obedience to core business } \\
\text { processes Linear IT } \\
\text { management structure }\end{array}$ & $\begin{array}{l}\text { Creation of systems } \\
\text { that automate certain } \\
\text { types of operations } \\
\text { with duplicate } \\
\text { functionality: } \\
\text { entering, grouping, } \\
\text { generating reports, } \\
\text { verifying and } \\
\text { controlling the data }\end{array}$ & $\begin{array}{l}\text { Management's unwillingness } \\
\text { to trust reports from IT } \\
\text { systems, repetitive actions } \\
\text { and excessive monitoring. } \\
\text { Incompatibility of various } \\
\text { systems }\end{array}$ \\
\hline Competitive (orange) & $\begin{array}{l}\text { Alignment with } \\
\text { corporate goals } \\
\text { Motivation of } \\
\text { innovations Parity of } \\
\text { responsibility and } \\
\text { authority }\end{array}$ & Service model & $\begin{array}{l}\text { Functional structure of IT } \\
\text { management } \\
\text { Engaging users into } \\
\text { development processes } \\
\text { Product system for } \\
\text { developing digital services } \\
\text { for functional departments } \\
\text { (ERP, HR, production } \\
\text { systems) } \\
\text { Production of own IT } \\
\text { products }\end{array}$ & $\begin{array}{l}\text { Creation of digital } \\
\text { services in the } \\
\text { interests of } \\
\text { individual divisions. } \\
\text { Enabling parameters } \\
\text { in the SLA (Service- } \\
\text { Level Agreements) } \\
\text { that reflect the local } \\
\text { KPIs of internal } \\
\text { divisions. } \\
\text { Unnecessary } \\
\text { operations that do } \\
\text { not add value to the } \\
\text { client. }\end{array}$ & $\begin{array}{l}\text { Dissatisfaction with the } \\
\text { response time to requests } \\
\text { from users of the main } \\
\text { business. } \\
\text { Constant increase in } \\
\text { expenses for maintenance } \\
\text { and development of IT } \\
\text { without increasing the quality } \\
\text { of provision of relevant } \\
\text { services, haphazard spending }\end{array}$ \\
\hline Pluralistic (green) & $\begin{array}{l}\text { Culture of values } \\
\text { Intangible motivation } \\
\text { Team spirit } \\
\text { Openness and mutual } \\
\text { assistance }\end{array}$ & Ecosystem & $\begin{array}{l}\text { Platform solutions that } \\
\text { involve all IT divisions and } \\
\text { other departments } \\
\text { Using Blockchain and } \\
\text { distributed registries to } \\
\text { verify actions } \\
\text { End-to-end integration of } \\
\text { the IT line into the } \\
\text { organization's products }\end{array}$ & $\begin{array}{l}\text { Weak use of the } \\
\text { potential of platform } \\
\text { solutions }\end{array}$ & $\begin{array}{l}\text { Unwillingness to generate } \\
\text { new services that improve the } \\
\text { efficiency of the core } \\
\text { business. } \\
\text { Excessive movement of } \\
\text { information to local } \\
\text { databases, proprietary nature } \\
\text { of a certain part of } \\
\text { information resources. }\end{array}$ \\
\hline Evolutionary (teal) & $\begin{array}{l}\text { Evolutionary goal } \\
\text { Integrity } \\
\text { Self-management }\end{array}$ & $\begin{array}{l}\text { IT-Prime - } \\
\text { Holacracy }\end{array}$ & $\begin{array}{l}\text { Artificial intelligence } \\
\text { Software robots and digital } \\
\text { assistants } \\
\text { Smart contracts }\end{array}$ & $\begin{array}{l}\text { Trust in formalized } \\
\text { algorithms, lack of } \\
\text { situational } \\
\text { awareness and } \\
\text { adaptation in IT } \\
\text { functionality. }\end{array}$ & $\begin{array}{l}\text { Waste of time performing } \\
\text { routine repetitive operations. } \\
\text { Loss of production resources, } \\
\text { lagging behind competitors. }\end{array}$ \\
\hline
\end{tabular}

Let us detail the table and trace the correlation between the stages of organizational development and those of the ITenvironment.

\section{A. Impulsive (red) - Patchwork Automation}

A basic level of maturity of IT-environment: plenty of manual processes, minimal centralization of management, illconceived or lacking policies and standards for system management and non-compliance with other IT standards. The company does not clearly understand the details of the existing IT-environment, and there is a lack of knowledge about its integration with business processes. The performance of services and applications is generally unknown due to the lack of suitable tools and resources. There is no mechanism for the exchange of accumulated knowledge between structural units of the organization.
Transition to the next level of maturity is made by eliminating the following types of losses:

In the organizational model:

- Lack of clarity for automation, lack of effectiveness, redundant operations that do not add value

In the IT management model:

- Mass losses of manual labour, loss of time of employees in the organization.

B. Conformist (brown)-IT-environment considered as a part of the core business infrastructure

In an organization at this level of maturity, standard procedures are applied that involve the use of IT expertise for the company's needs: knowledge sharing tools are emerging, policies and standards are being rolled out, best practices are 
being applied, but the response to organizational challenges remains weak - there is mistrust between the core unit and the IT-environment, there are data verification issues, and there is a lack of integration between systems and hierarchies.

Transition to the next level of maturity is made by eliminating the following types of losses:

In the organizational model:

- Creation of systems that automate certain types of operations with duplicate functionality: entering, grouping, generating reports, verifying and controlling the data.

In the IT management model:

- Management's unwillingness to trust reports from IT systems, repetitive actions and excessive monitoring.

Incompatibility of various systems.

\section{Competitive (orange)-Service model}

This level of IT maturity of the organization is characterized by the minimum cost of managing the hardware part. Policies and processes are becoming important in expanding and supporting the business. The key focus in protection is on preventative measures, the company reacts predictably and quickly to any kind of security threats, integrity of business processes involving automation. "Zero touch deployment" (fully automated deployment, with minimal operator involvement) reduces costs and human factor involvement. The IT-environment at this stage provides business with a large number of bonuses: an enterprise becomes capable of introducing alternative and new technologies required for the implementation of new goals and business objectives, while the winnings significantly exceed the additional costs.

Transition to the next level of maturity is made by eliminating the following types of losses:

In the organizational model:

- Creation of digital services in the interests of individual divisions. Enabling parameters in the SLA (ServiceLevel Agreements) that reflect the local KPIs of internal divisions.

- Unnecessary operations that do not add value to the client.

In the IT management model:

- Dissatisfaction with the response time to requests from users of the main business.

- Constant increase in expenses for maintenance and development of IT without increasing the quality of provision of relevant services, haphazard spending.

\section{Pluralistic (green) - Ecosystem}

In an organization with IT-environment at the ecosystem level, there is a full understanding of the strategic value of this environment, which contributes to effective business management and the constant outpacing of competitors. Processes become fully automated and are regularly incorporated directly into IT systems, allowing these systems to be managed according to business needs. Fast and predictable returns to the business are provided by additional investments into technology. Enterprises with this level of IT maturity can respond to any challenge of modern business.

Transition to the next level of maturity is made by eliminating the following types of losses:

In the organizational model:

- Weak use of the potential of platform solutions

- Excessive movement of information to local databases, proprietary nature of a certain part of information resources.

In the IT management model:

- Excessive movement of information to local databases, proprietary nature of a certain part of information resources.

The next stage of IT-environment development after the ecosystem is evolutionary, analogous to the teal one. It is often compared to the popular U.S. trend of organizational development - holacracy.

\section{E. IT-Prime - Holacracy}

The term "Holacracy" comes from the term "cholarchy", first introduced by Arthur Koestler in 1967 [14]. Holacracy consists of "holons", or otherwise autonomous and selfsufficient units, dependent on the larger whole of which they are a part. Thus, holacracy is a hierarchy of self-regulating holons that function simultaneously as autonomous whole units and as dependent parts.

The system of holacracy was born at Ternary Software (USA) when its founder Brian Robertson developed [15] an organizational system which became known as Holacracy in 2007. Subsequently, in 2010 Robertson wrote the "Holacracy Constitution", in which he laid out the basic principles and methods of operation of the system, and began to support companies in its implementation.

The traditional departments in a holacracy company have been replaced [16] by a hierarchy of "circles" - teams that can assemble for a specific project or for similar tasks. In "circles" there are people who would work in different departments in a traditional company, separated by a wall. The management of the company builds a hierarchy of "circles", deciding which "circle" is subordinate to the other. Instead of the usual positions, the roles that employees themselves distribute within their "circle". They decide how to organize their work. As a rule, each employee performs several roles. However, a role is not a job description, but a specific task that a person has to perform for some time. As soon as there are new projects, things change, the employee gets a new role. roles:

Manager responsibilities are divided into four management

- Lead Link. This person is assigned to the circle by an external circle and transmits information to them from outside. This is not a boss, his job is either to fill the circle with participants with relevant competences or to perform their functions themselves.

- Rep Link. Feedback channel - transmits internal problems of the circle to the external circle. It is chosen by the participants in the circle. 
- Secretary. A participant in the circle who coordinates meetings and collects their results.

- Facilitator. The leader of the circle meetings - like the secretary, he is chosen by the other circle participants.

Apart from these roles, the circle participants have functional roles. Only the person himself or herself can prioritize his or her functional role, but the leader link can remove him or her from the circle if he or she fails or prevents the other participants from fulfilling their roles.

A flat organization means that the circles are equal with each other. Each Circle is central to its purpose. They communicate with each other through a waiting mechanism. In addition to the basic principles of the Circles, their selforganization mechanism is based on two main entities - the Waiting and the Promise.

The Waiting is the very request to perform a task or provide a resource. The Promise is an agreement on the part of the Circle to fit into a specific activity or to provide the required resource.

It is in such organizations that you should expect the flourishing of smart contract technology, software robots, AI and Big Data [17].

However, losses also occur in teal organizations: In the organizational model:

- Trust in formalized algorithms, lack of situational awareness and adaptation in IT functionality.

In the IT management model:

- Waste of time performing routine repetitive operations.

- Loss of production resources, lagging behind competitors.

\section{CONCLUSIONS}

According to Don Beck and Chris Cowan [18], the need for change always arises from the mismatch between the current structure of an organization and its environment. Such conflict leads to two development options: evolutionary development, or the accumulation of discord that will then require revolution or lead to death for the organization. Thus, in a competitive environment, almost any organization has to evolve. Given that in today's digital economy the level of maturity of IT systems is so high that whole ecosystems are beginning to rule the world, the demand for "teal" practices will only grow naturally.

Correlation between the organizational evolution and evolution of IT-environment is clear: synergy and synchronization of paces for these two categories are required to achieve success and evolve.

Companies from various sectors around the world are following already this path of evolutionary development in organizational and IT sense, including Zappos, Patagonia, AES, The Morning Star, etc. In Russia there are VkusVill, Sber, QIWI and many others. Achievement of the teal level through elimination of losses and development of the ITenvironment is taking place before our eyes and leads to global shifts in the very concepts of business models, involvement of organizations in the digital economy, as well as opens up new approaches in studying organizational development.

\section{ACKNOWLEDGMENTS}

The authors would like to thank the staff of the Russian University of Transport, LEAN GLOBAL NETWORK and ITSMF.

\section{REFERENCES}

[1] N. Geada, "Change management in the digital economy: mode proposal”, IJIDE, 2020, vol. 11(3), pp. 37-51. DOI: https/doi.org/10.4018/IJIDE.2020070103

[2] S. Chou, "The fourth industrial revolution: digital fusion with internet of things", Journal of International Affairs, 2018, vol. 72(1), pp. 107-120, Retrieved from https://www.jstor.org/stable/26588346

[3] P. Milgrom and J. Roberts, "The economics of modern manufacturing technology, strategy, and organization", The American Economic Review, 1990, vol. 80(3), pp. 511-528, http://www.jstor.org/stable/2006681

[4] Andri, Paulus, Hanes and N.P. Wong, "Measuring the maturity level of ITSM using ITIL framework", in Proceedings of Fourth International Conference on Informatics and Computing (ICIC), 2019, pp. 1-6. DOI: https/doi.org/10.1109/ICIC47613.2019.8985879

[5] C.W. Graves, "Levels of existence: an open system theory of values", The Journal of Humanistic Psychology, 1970, vol. 10, pp. 131-154

[6] A. Butters, "A brief history of Spiral Dynamics", AR, 2015, vol. 5, pp. 67-78. DOI: https/doi.org/10.30664/ar.67574

[7] F. Laloux, "Reinventing Organizations: A Guide to Creating Organizations Inspired by the Next Stage of Human Consciousness", Nelson Parker, 2014.

[8] D.V. Antipov, G.V. Akhmetzhanova, O.I. Antipova, A.U. Gazizulina and R. Sharov, "Organizational models of teal organizations", in Proceedings of 6th International Conference on Reliability, Infocom Technologies and Optimization (Trends and Future Directions) (ICRITO), 2017, pp. 222-230. (In Russ.). DOI: https/doi.org/10.1109/ICRITO.2017.8342428

[9] B. Wyrzykowska, "Teal organizations: literature review and future research directions", Journal of Management and Business Administration. Central Europe, 2019, vol. 27(4), pp. 124-141. DOI: https/doi.org/10.7206/cemj.2658-0845.12

[10] M. Annosi, A. Martini and L. Marchegiani, "Learning in an Agile Setting: A Multilevel Study on the Evolution of Organizational Routines", Journal of Business Research, 2018, vol. 110, pp. 554-566. DOI: https/doi.org/10.1016/j.jbusres.2018.05.011

[11] A. Rezaei, S.M. Allameh and R. Ansari, "Effect of organisational culture and organisational learning on organisational innovation: an empirical investigation". International Journal of Productivity and Quality Management, 2018, vol. 23(3), pp. 307-327. DOI: https/doi.org/10.1504/ijpqm.2018.089803

[12] H. Gunawan, "Strategic management for it services using the information technology infrastructure library (ITIL) framework", in Proceedings of International Conference on Information Management and Technology (ICIMTech), 2019, pp. 362-366. DOI: https/doi.org/10.1109/ICIMTech.2019.8843711

[13] G. Manjul, J.F. George and W. Xia, "Relationships between IT department culture and agile software development practices: An empirical investigation", International Journal of Information Management, 2019, vol. 44, pp. 13-24. DOI: https/doi.org/10.1016/j.ijinfomgt.2018.09.006

[14] A. Koestler, "The Ghost in the Machine", (1990 reprint ed.), Penguin Group, 1967.

[15] R. Bhandari and R. Colomo-Palacios, "Holacracy in software development teams: a multivocal literature review", in Proceedings of 19th International Conference on Computational Science and Its Applications (ICCSA), 2019, pp. 140-145. DOI: https/doi.org/10.1109/ICCSA.2019.00013 
[16] G. Savage, A. Franz and J.S. Wasek, "A holacratic socio-technical system architecture", in Proceedings of IEEE International Symposium on Systems Engineering (ISSE), 2016, pp. 1-6, DOI: https/doi.org/10.1109/SysEng.2016.7753191

[17] R. Foresti, S. Rossi, M. Magnani, C.G. Lo Bianco and N. Delmonte, "Smart society and Artificial Intelligence: Big Data scheduling and the
Global Standard Method applied to smart maintenance", Engineering, 2020, vol. 6(7), $\quad$ pp. DOI: https/doi.org/10.1016/j.eng.2019.11.014

[18] D. Beck and C. Cowan, "Spiral Dynamics: Mastering Values, Leadership, and Change”. Blackwell Publishing, 1996. 